\title{
Identifying the barriers and enablers for a triage, treatment, and transfer clinical intervention to manage acute stroke patients in the emergency department: a systematic review using the theoretical domains framework (TDF)
}

Louise E. Craig $^{1 *}$, Elizabeth Mclnnes ${ }^{1}$, Natalie Taylor ${ }^{2}$, Rohan Grimley ${ }^{3}$, Dominique A. Cadilhac ${ }^{4,5}$, Julie Considine ${ }^{6,7}$ and Sandy Middleton ${ }^{1}$

\begin{abstract}
Background: Clinical guidelines recommend that assessment and management of patients with stroke commences early including in emergency departments (ED). To inform the development of an implementation intervention targeted in $E D$, we conducted a systematic review of qualitative and quantitative studies to identify relevant barriers and enablers to six key clinical behaviours in acute stroke care: appropriate triage, thrombolysis administration, monitoring and management of temperature, blood glucose levels, and of swallowing difficulties and transfer of stroke patients in ED.

Methods: Studies of any design, conducted in ED, where barriers or enablers based on primary data were identified for one or more of these six clinical behaviours. Major biomedical databases (CINAHL, OVID SP EMBASE, OVID SP MEDLINE) were searched using comprehensive search strategies. The barriers and enablers were categorised using the theoretical domains framework (TDF). The behaviour change technique (BCT) that best aligned to the strategy each enabler represented was selected for each of the reported enablers using a standard taxonomy.

Results: Five qualitative studies and four surveys out of the 44 studies identified met the selection criteria. The majority of barriers reported corresponded with the TDF domains of "environmental, context and resources" (such as stressful working conditions or lack of resources) and "knowledge" (such as lack of guideline awareness or familiarity). The majority of enablers corresponded with the domains of "knowledge" (such as education for physicians on the calculated risk of haemorrhage following intravenous thrombolysis [tPA]) and "skills" (such as providing opportunity to treat stroke cases of varying complexity). The total number of BCTs assigned was 18. The BCTs most frequently assigned to the reported enablers were "focus on past success" and "information about health consequences."

(Continued on next page)
\end{abstract}

\footnotetext{
* Correspondence: Louise.Craig@acu.edu.au

${ }^{1}$ Nursing Research Institute, St Vincent's Health Australia (Sydney) and

Australian Catholic University, Sydney, NSW, Australia

Full list of author information is available at the end of the article
} 
(Continued from previous page)

Conclusions: Barriers and enablers for the delivery of key evidence-based protocols in an emergency setting have been identified and interpreted within a relevant theoretical framework. This new knowledge has since been used to select specific BCTs to implement evidence-based care in an ED setting. It is recommended that findings from similar future reviews adopt a similar theoretical approach. In particular, the use of existing matrices to assist the selection of relevant BCTs.

Keywords: Implementation, Barriers, Enablers, Theoretical domains framework, Acute stroke, Emergency department

\section{Background}

Clinical guidelines recommend that the assessment and management of patients with stroke should commence early in the pre-hospital setting and hospital emergency department (ED) [1]. Despite the recent advances in interventions for the management of acute stroke, only a small proportion of individuals receive recommended evidence-based treatment in the hours following acute stroke $[1,2]$. For example, thrombolysis using intravenous tissue plasminogen activator (tPA) is currently one of the few evidence-based treatments available for acute ischaemic stroke, however, internationally rates are variable, ranging from $5 \%$ in the USA [3] to $14 \%$ in some European Centres [4]. Furthermore, outcomes are improved by early administration (within hours) of tPA after symptom onset. However, in-hospital delays are often a significant obstacle in achieving early administration of tPA [5].

Determining the inhibiting factors (barriers) and supporting factors (enablers) for implementation of research evidence, is a well-established requirement to improve the quality of patient care [6]. It has been demonstrated that a theoretical approach to assessing barriers and enablers can effectively be used for developing tailored informed strategies to support the effective implementation of evidence-based practices, such as hand hygiene [7]. Systematic reviews offer a way to synthesise the broad range of barriers and enablers reported in individual studies and provide a broader understanding of the influences on evidence-based treatment uptake. Findings from such reviews can be used to inform the development of effective interventions to implement evidencebased care in clinical settings.

In stroke, systematic reviews have been conducted to identify barriers and enablers to implementing elements of stroke guidelines. These have usually been studied at an organisational level and have included pre-admission barriers such as non-recognition of stroke [8], triaging of stroke as non-urgent by both ED and ambulance staff $[8,9]$, delays in accessing imaging [8] and inefficient hospital processes and protocols $[8,9]$. Data included in these reviews were based on retrospective analyses of hospital databases $[5,10]$ national registries [11], or prospective cohort data. The main limitation of these reviews is that the barriers and/or enablers were based on the authors' perceptions or explanations rather than based on healthcare staffs' perceptions or beliefs.

Recently, within the implementation science literature there has been increasing importance placed on the development of behaviour change interventions [12, 13] using theoretical models or frameworks such as the Theoretical Domains Framework (TDF) [14]. The use of theory is important to understand the factors that influence healthcare professionals' behaviours, to inform the use of possible behaviour change techniques (BCTs) and to provide clarity as to how these techniques might work $[15,16]$. Interventions are said to be more effective if interventions are based on evidence-based principles drawn from theories of behaviour and behaviour change [17].

The TDF is a framework of originally 12 domains [14] (now 14 domains [18]). The theoretical domains were derived from 33 behaviour change theories and developed using a process of expert consensus with subsequent validation work. To facilitate the application of $\mathrm{BCT}$ taxonomy and to assist the selection of relevant BCTs a matrix has been developed which is based on identifying links between specific BCTs and theoretical constructs such as those used in the TDF [19]. The TDF has been used in a number of healthcare settings to study implementation and more specifically assist in the development of implementation interventions [16]. The TDF has also been used as a coding framework for the analysis of barriers in systematic reviews [20-22]. In one study the TDF allowed the researchers to explore, explain and potentially target, using sophisticated behaviour change interventions, complex relationships, for example, limited "knowledge" appeared to influence healthcare professional's 'emotions' [21].

In the Quality in Acute Stroke Care Study (QASC) the investigators demonstrated significant benefits for patients who were cared for in acute stroke units (ASU) in which staff had received support for implementation of protocols to manage fever, hyperglycaemia, and swallowing dysfunction [23]. The QASC trialists recommended future trials to examine the multidisciplinary intervention in other 
settings, such as the ED, to ensure patients had rapid access to these evidence-based protocols [23]. Prior to the development of an implementation intervention to deliver such evidence-based protocols, we undertook a systematic review of qualitative and quantitative studies to identify the barriers and enablers specific to an ED setting. The findings from this systematic review will inform the use of specific BCTs to develop an implementation intervention.

\section{Aim}

The aims of this systematic review were to:

- Identify the reported barriers and enablers to implementing the following evidence-based care elements (hereonin referred to as target clinical behaviours): appropriate triage, thrombolysis administration, monitoring and management of temperature, blood glucose levels, and of swallowing difficulties and rapid (within $4 \mathrm{~h}$ of arrival to ED) transfer to the ASU

- Classify reported barriers and facilitators using the TDF

- Select the BCT that best aligned to the strategy each enabler represented using standard taxonomy

\section{Methods}

\section{Inclusion and exclusion criteria}

Studies were eligible for inclusion, regardless of design, if the study:

- Aim was to identify the barriers and/or enablers for any one or a combination of the target clinical behaviours in the ED of a hospital (Table 1) and

- Included the views/perceptions of healthcare professionals regarding the target behaviours who worked in ED.
Abstracts, letters, editorials, and commentaries were excluded. No restrictions were placed on country, written language, or year of publication.

\section{Search methods for identification of studies}

The search strategy was developed using search concepts (groups of words; Appendix). Potentially relevant studies were identified through a search (inception to August 2016) of the following electronic databases: CINAHL, OVID SP EMBASE, OVID SP MEDLINE, and Web of Science. Other databases that were searched included: OVID SP PubMed Central; The Joanna Briggs Institute EBP; Database ProQuest Dissertations \& Theses Full Text. The following grey literature databases also were searched: Agency for Healthcare Research and Quality (AHRQ); Open Grey and Grey Literature Report.

The Science Citation Index (Web of Science) was searched to identify further studies that had cited the studies included in the review. Reference lists of included publications were searched to identify additional studies.

\section{Search strategy}

The search strategy applied to the databases was a combination of Medical Subject Headings (MeSH) terms such as: "Health Plan Implementation" and "EvidenceBased Practice", as well as additional keywords such as "barrier", "uptake," and "enabler", and relevant synonyms. The MeSH terms and keywords were generated for each of the search concepts by examining the terminology and database indexing used in relevant papers. The search strategies were reviewed by a University Librarian with experience in database searches, prior to the search being undertaken.

Table 1 Target clinical behaviours

\begin{tabular}{ll}
\hline Clinical behaviour & Description \\
\hline Triage & All patients presenting with signs and symptoms of suspected acute stroke should be triaged as \\
& Australian Triage Scale Category or 2 (seen within 10 mins) \\
Thrombolysis & All patients to be assessed for tPA eligibility \\
& All eligible patients to receive tPA \\
Management of temperature & All patients to have their temperature taken on arrival to Emergency Department (ED) and then at \\
& least four hourly whilst they remain in ED \\
& Temperature $37.5^{\circ} \mathrm{C}$ or greater to be treated with paracetamol (acetaminophen) within one hour \\
Management of blood glucose levels & Venous blood glucose level (BGL) sample sent to laboratory on admission to ED \\
& Finger prick BGL recorded on admission and finger prick BGL monitored every $6 \mathrm{~h}$ (or greater if \\
& elevated) \\
Insulin administered to all patients with BGL $>10$ mMol/L within one hour \\
Swallow assessment & Patients to remain nil by mouth until a swallow screen by non- Speech Pathologist (SP) or swallow \\
& assessment by SP performed \\
Transfer & All patients who fail the screen to have a swallowing assessment by a SP \\
& All patients with stroke to be discharged from ED within $4 \mathrm{~h}$ \\
& All patients with stroke to be admitted to the hospital's stroke unit \\
\hline
\end{tabular}




\section{Screening process}

The titles and abstracts of retrieved references from the search were screened by a single reviewer to exclude obviously irrelevant studies. The full article of any study that met the inclusion criteria was reviewed by at least two of the authors (EM, LC, or SM).

\section{Data extraction}

Data were extracted using a standardised form by one reviewer (LC), with a sub-set of included papers $(n=15$ [30\%]) being extracted by a second reviewer (EM or SM). Data collection included full study characteristics such as author, date of publication, study design and the reported study findings, i.e., barriers and/or enablers. Barriers and/or enablers based on primary data were extracted using theme headings and theme descriptions in qualitative studies and extracted from tables presenting questionnaire responses to pre-specified barriers and/or enablers in the quantitative studies (Table 2). Six of the nine included studies [24-29] focused on one target behaviour which was easily identifiable from the title on screening and the aim and method sections on data extraction. The remaining three studies [30-32] focused on stroke pathways or key stroke care recommendations whereby the target behaviours of interest were identified in the methods and results sections of the individual studies. If the lead author was unclear which target behaviour the data represented this was cross-checked and discussed with another author (SM or EM). Authors of included studies did not distinguish between modifiable and non-modifiable barriers/enablers.

\section{Qualitative studies}

Verbatim supporting quotes, where available, were extracted to illustrate the barriers and enablers. Author interpretations or findings from secondary analysis of routine data were not included.

\section{Quantitative studies}

To ensure that the review presented findings that were representative and important, certain decisions were made about the data extraction for the survey data. Prespecified barriers where zero or only one of the participants selected were not extracted [26, 29]. A decision was made to extract only the pre-specified barriers where the majority of participants agreed $(>50 \%)$ for one study [25] and a further decision was made to extract pre-specified barriers which scored a level of agreement $>3$ ( $1=$ fully disagree; $5=$ fully agree) for the remaining survey [32].

\section{Quality assessment}

Quality assessment of qualitative studies was conducted using the Critical Appraisal Skills Programme Qualitative
Checklist (CASP) [33]. For the assessment of quantitative studies the Centre for Evidence-Based Management "Appraisal of a Survey" tool was used [34]. Critical appraisal was conducted by one reviewer (LC) for all studies, with second reviewer appraisal (EM or SM) for a subset of included papers (the same sub-set subject to second reviewer data extraction). The findings from the two reviewers were compared and any contrasting items were discussed and re-reviewed to reach an agreement.

\section{Data analysis}

The extracted data were classified using the TDF [18]. Classification of barriers and enabler data was conducted independently by two researchers experienced in the application of the TDF (LC and NT). Reference was made to the original article regarding the development of the TDF to ensure accurate interpretation of the domains [14]. The TDF constructs [18] and contextual information reported for an individual barrier/enabler were also used to allocate the data to the most appropriate domain. Using the descriptors of each TDF domain, the individual barriers and enablers were classified accordingly. There were two disagreements between the two researchers resulting in the re-classification of two barriers, one from the beliefs about capabilities domain to the social influences domain and the other from the beliefs about capabilities domain to the intentions domain. The TDF was used as a relevant framework to narratively summarise the individual barriers under the relevant theoretical domains; but no thematic synthesis was conducted to identify themes.

\section{Allocating BCT labels to reported enablers}

A matrix which assigns the most appropriate BCT to each of the TDF domains has already been developed by Cane et al. [35]. Primarily, this resource has been used in the past to develop behaviour change interventions to address identified key barriers. However, the studies included in our review did not report strategies to overcome specific barriers, so BCTs could not be assigned. However, the enablers reported in each study were able to be aligned with BCTs listed in the Cane matrix, as each reported enabler essentially represented a strategy to promote behaviour. The $\mathrm{BCT}$ that best aligned to the enabling strategy was then selected for each of the reported enablers using this matrix [36]. The assignment of BCTs to enablers was independently conducted by two researchers. Both researchers then discussed the allocations collectively and resolved any disagreements by discussion. This approach to classifying enablers to $\mathrm{BCT}$ enhances reporting as it provides a standardised label for the reported enabler using a common BCT taxonomy and subsequently increases the transferability of the findings. 
Table 2 Characteristics of included studies

\begin{tabular}{|c|c|c|c|c|c|}
\hline Author/date & Aim of study & Design & $\begin{array}{l}\text { Method of data } \\
\text { collection }\end{array}$ & $\begin{array}{l}\text { Source of barrier/enabler } \\
\text { data extraction }\end{array}$ & Participants \\
\hline $\begin{array}{l}\text { Daniels et al. (2013) [24] } \\
\text { USA }\end{array}$ & $\begin{array}{l}\text { To identify strategies for effective implementation } \\
\text { of swallowing screening in patients with stroke } \\
\text { symptoms that presented in ED }\end{array}$ & Qualitative & Staff interviews & Barrier and enabler themes & ED nurses $(n=8)$ \\
\hline $\begin{array}{l}\text { Gache et al. (2014) [30] } \\
\text { France }\end{array}$ & $\begin{array}{l}\text { To identify the main barriers to effective } \\
\text { implementation of Stoke Care Pathway in France }\end{array}$ & Qualitative & $\begin{array}{l}\text { Semi-structured } \\
\text { interviews }\end{array}$ & $\begin{array}{l}\text { Barrier typology derived } \\
\text { from data }\end{array}$ & $\begin{array}{l}\text { Emergency physicians, neurologists, } \\
\text { geriatricians, social workers, health } \\
\text { care workers in rehab and nursing } \\
\text { homes }(n=33)\end{array}$ \\
\hline $\begin{array}{l}\text { Grady et al. (2014) [25] } \\
\text { Australia }\end{array}$ & $\begin{array}{l}\text { To assess emergency physicians' perceptions of } \\
\text { individual and system enablers to the use of } \\
\text { thrombolysis in acute stroke }\end{array}$ & $\begin{array}{l}\text { A web-based } \\
\text { survey }\end{array}$ & Questionnaire & $\begin{array}{l}\text { Responder's agreement to } \\
\text { pre-defined enabler statements }\end{array}$ & $\begin{array}{l}\text { Australian fellows and trainees } \\
\text { registered with ACEM }(n=429)\end{array}$ \\
\hline $\begin{array}{l}\text { Hargis et al. (2015) [26] } \\
\text { USA }\end{array}$ & $\begin{array}{l}\text { To identify factors that may limit the administration } \\
\text { of rt-PA in the emergency department at multiple } \\
\text { stroke centres }\end{array}$ & $\begin{array}{l}\text { A web-based } \\
\text { survey }\end{array}$ & Questionnaire & $\begin{array}{l}\text { Responder's agreement to } \\
\text { pre-defined enabler statements }\end{array}$ & ED nurses and pharmacists $(n=37)$ \\
\hline $\begin{array}{l}\text { Johnson MJ et al. (2011) } \\
\text { [31] USA }\end{array}$ & $\begin{array}{l}\text { To describe emergency nurses' perceptions of } \\
\text { specific barriers and enablers to the care of stroke } \\
\text { patients in the emergency department }\end{array}$ & Qualitative & Focus groups & Barrier and enabler themes & $\begin{array}{l}\text { Emergency nurses currently employed } \\
\text { in an emergency department }(n=10)\end{array}$ \\
\hline Meuer et al. (2011) USA & $\begin{array}{l}\text { To describe the pre-identified barriers to clinicians } \\
\text { compliant with guidelines recommending the use } \\
\text { of thrombolysis }\end{array}$ & Qualitative & $\begin{array}{l}\text { Focus groups and } \\
\text { one-to-one interviews }\end{array}$ & $\begin{array}{l}\text { Barrier listed in the coding } \\
\text { guide with definitions }\end{array}$ & $\begin{array}{l}\text { Emergency physicians, nurses, } \\
\text { neurologists, radiologists, hospital } \\
\text { administrators, and hospitalists and } \\
\text { pharmacist }(n=30)\end{array}$ \\
\hline $\begin{array}{l}\text { Skecksen A et al. (2014) } \\
\text { Sweden }\end{array}$ & $\begin{array}{l}\text { To identify and analyse the barriers and enablers to } \\
\text { implementing national thrombolytic guidelines }\end{array}$ & Qualitative & $\begin{array}{l}\text { Semi-structured } \\
\text { interviews }\end{array}$ & Barrier and enabler themes & $\begin{array}{l}\text { Stroke healthcare professionals (nurses } \\
\text { and physicians) }(n=16)\end{array}$ \\
\hline $\begin{array}{l}\text { Van Der Weijden et al. } \\
\text { (2004) [32] The Netherlands }\end{array}$ & $\begin{array}{l}\text { To explore the opinion on possible barriers for } \\
\text { working according to key recommendations for the } \\
\text { acute phase a stroke care among neurologists }\end{array}$ & $\begin{array}{l}\text { Paper-based } \\
\text { survey }\end{array}$ & Questionnaire & $\begin{array}{l}\text { Responder's agreement to } \\
\text { pre-defined barrier statements }\end{array}$ & Registered neurologists $(n=16)$ \\
\hline $\begin{array}{l}\text { Williams J et al. (2013) [29] } \\
\text { Australia }\end{array}$ & $\begin{array}{l}\text { To identify barriers which prevent rural health care } \\
\text { providers from utilising thrombolysis in acute } \\
\text { ischamic stroke }\end{array}$ & $\begin{array}{l}\text { Paper-based } \\
\text { survey }\end{array}$ & Questionnaire & $\begin{array}{l}\text { Responder's agreement to } \\
\text { pre-defined barrier statements }\end{array}$ & $\begin{array}{l}\text { All rural sites within NSW Australia that } \\
\text { had an implemented thrombolysis } \\
\text { service as defined by the NSF and an } \\
\text { Stroke Care Coordinator position were } \\
\text { deemed eligible for inclusion }(n=11)\end{array}$ \\
\hline
\end{tabular}

ACEM Australasian College for Emergency Medicine, ED Emergency Department, NSF National Stroke Foundation 


\section{Results}

The search identified 2114 studies. Following the initial screening of titles and abstracts, duplicate and irrelevant studies were excluded, and the full-text articles of 44 studies were assessed in detail (Fig. 1). One further article was identified through citation searching. No further articles were identified from reviewing the reference lists of the included studies. Overall, nine studies met the selection criteria and were included in the review [24-32].

\section{Study characteristics}

Table 2 shows the characteristics of the nine studies which were all published between 2004 and 2015. Five studies were qualitative with one using focus group methods [31] and four using semi-structured interviews $[24,27,28,30]$. The remaining four studies used a survey method, of which two used an online questionnaire $[25,26]$. The sample sizes ranged from 8 to 429 healthcare professionals. Four studies were conducted in the USA, two in Australia, one in Sweden, one in the Netherlands, and one in France. Sampling strategies to recruit participants varied. In five studies a convenience sample was used [24, 25, 29, 31, 32] and in four studies a purposive sampling strategy was used $[26-28,30]$.

In one study, barriers and enablers relating to the triage behaviour were identified [31]. In four studies, barriers and enablers relating to the tPA related behaviours were reported [25, 27-29]. One study only reported barriers (i.e. no enablers) to the tPA related behaviours [26] and one study reported the barriers for both the tPA and transfer related behaviours [32]. In another study, the barriers and enablers relating to both the tPA and the triage related behaviours were reported [30]. Lastly, barriers and enablers to the swallow assessment behavior were reported in a single study [24]. None of the included studies provided evidence on the barriers and enablers for behaviours relating to management of fever, or for the management of blood glucose levels.

\section{Quality of the included studies}

The common limitations within the qualitative studies were: no or little information about the relationship between the researcher and participants [24, 27, 28, $30,31]$, and a lack of data describing and justifying the approach for analysis [24, 28, 31]. Generally, the strengths of the studies were clearly stated aims, appropriate use of methods and a clear statement of findings (Table 3).

With regard to the quality of the quantitative research (Table 4), the low response rates (13-55\%) limits the potential generalisability of these studies. All of these studies had a clearly defined research question.

\section{Participant characteristics}

The nine included studies provided data from 590 healthcare professionals working in a hospital ED. In two studies, the mean age of participants was reported

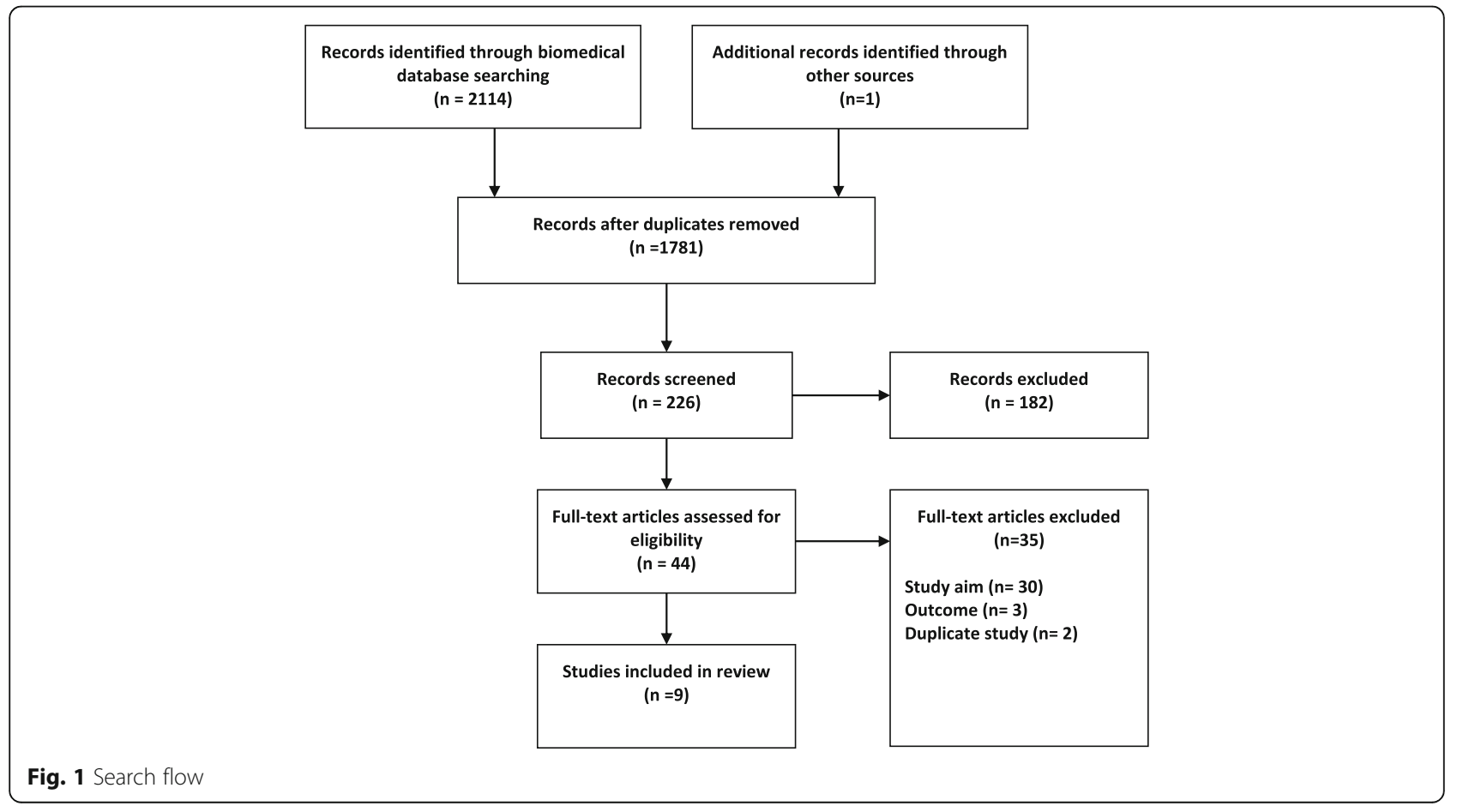


Table 3 Quality assessment results of qualitative included studies

\begin{tabular}{|c|c|c|c|c|c|}
\hline Quality assessment question & $\begin{array}{l}\text { Daniels et al., } \\
2013[24]\end{array}$ & $\begin{array}{l}\text { Gache et al., } \\
2014[30]\end{array}$ & $\begin{array}{l}\text { Johnson et al., } \\
2011[31]\end{array}$ & $\begin{array}{l}\text { Meuer et al., } \\
2011\end{array}$ & $\begin{array}{l}\text { Skecksen et al., } \\
2014\end{array}$ \\
\hline Was there a clear statement of the aims of the research? & $\checkmark$ & $\checkmark$ & $\checkmark$ & $\checkmark$ & $\checkmark$ \\
\hline Is a qualitative methodology appropriate? & $\checkmark$ & $\checkmark$ & $\checkmark$ & $\checkmark$ & $\checkmark$ \\
\hline Was the research design appropriate to address the aims of the research? & $\checkmark$ & $\checkmark$ & $\checkmark$ & $\checkmark$ & $\checkmark$ \\
\hline Was the recruitment strategy appropriate to the aims of the research? & $\checkmark$ & $\checkmark$ & $\checkmark$ & $\checkmark$ & $x$ \\
\hline Was the data collected in a way that addressed the research issue? & $\checkmark$ & $\checkmark$ & $\checkmark$ & $\checkmark$ & $\checkmark$ \\
\hline $\begin{array}{l}\text { Has the relationship between researcher and participants been } \\
\text { considered? }\end{array}$ & $x$ & $x$ & Not reported & $x$ & $x$ \\
\hline Have ethical issues been taken into consideration? & $\checkmark$ & $\checkmark$ & Not reported & $\checkmark$ & $\checkmark$ \\
\hline Was the data analysis sufficiently rigorous? & $x$ & $\checkmark$ & Not reported & $\checkmark$ & $x$ \\
\hline Is there a clear statement of findings? & $\checkmark$ & $\checkmark$ & Not reported & $\checkmark$ & $\checkmark$ \\
\hline How valuable is the research? & $\checkmark$ & $\checkmark$ & $\checkmark$ & $\checkmark$ & $\checkmark$ \\
\hline
\end{tabular}

$\mathrm{X}=\mathrm{No} ; \checkmark=$ Yes

(41.1 years [25] and 33.9 years [31]). Out of the four studies where the sex of participants was provided, the percentages that were female ranged from $13.5 \%$ [32] to $100 \%$ [31]. The type of participants were all nurses in two studies [24, 31], physicians and nurses in the remaining seven studies, of which four of these included participation by other disciplines such as social workers or pharmacists [25-27, 30]. The length of experience working in the ED was reported in two studies and ranged from the majority of participants having worked in ED over 10 years [25] and between 1 month and less than 17 months [30].

\section{Domains of the TDF as represented by the reported barriers and enablers}

A summary of barriers and enablers by TDF domain as identified in each of the included studies is provided in Table 5. The review identified 51 barriers and 40 enablers relevant to the target clinical behaviours. The number of barriers and number of enablers reported for triage behaviour were nine and one, respectively. The number of barriers and number of enablers reported for the thrombolysis related behaviours were 21 and 36, respectively. The number of barriers and number of enablers reported for swallow assessment behaviour were four and three, respectively. Only one barrier was reported for transfer-related behaviours.

\section{Knowledge}

Barrier and enabler data were available relating to triage and tPA-related behaviours. Both studies investigating triage reported "stroke was not being recognised as a priority" as a barrier [30, 31]. All three studies for the tPA-related behaviours identified barriers associated with lack of knowledge including guideline unfamiliarity [27], awareness [27], or failure to react to deviations in

Table 4 Quality assessment results of quantitative included studies

\begin{tabular}{|c|c|c|c|c|}
\hline Quality assessment question & $\begin{array}{l}\text { Grady et al., } \\
2014 \text { [25] }\end{array}$ & $\begin{array}{l}\text { Hargis et al., } \\
2015 \text { [26] }\end{array}$ & $\begin{array}{l}\text { Williams J et al., } \\
2013 \text { [29] }\end{array}$ & $\begin{array}{l}\text { Van Der Weijden et al., } \\
2004 \text { [32] }\end{array}$ \\
\hline Did the study address a clearly focused question/issue? & $\checkmark$ & $\checkmark$ & $\checkmark$ & $\checkmark$ \\
\hline Is the research method appropriate? & $\checkmark$ & $x$ & $x$ & $x$ \\
\hline Is the method of selection of the subjects clearly described? & $\checkmark$ & $\checkmark$ & $\checkmark$ & $\checkmark$ \\
\hline Could the way the sample was obtained introduce bias? & Not reported & $x$ & Not reported & $x$ \\
\hline Was the sample of subjects representative with regard to the population? & $\checkmark$ & $\checkmark$ & Not reported & $\checkmark$ \\
\hline Was the sample size based on considerations of statistical power? & $x$ & $x$ & $x$ & $\checkmark$ \\
\hline Was a satisfactory response rate achieved? & $x$ & $\checkmark$ & $x$ & $\checkmark$ \\
\hline Are the measurements likely to be valid and reliable? & Not reported & $\checkmark$ & Not reported & $\checkmark$ \\
\hline Was the statistical significance assessed? & $\checkmark$ & $x$ & $x$ & $x$ \\
\hline Are confidence intervals given for the main results? & $x$ & $x$ & $x$ & $\checkmark$ \\
\hline Could there be confounding factors that haven't been accounted for? & $x$ & $x$ & $x$ & Not reported \\
\hline Can the results be applied to your organisation? & Not reported & $\checkmark$ & Not reported & $\checkmark$ \\
\hline
\end{tabular}

$\mathrm{X}=\mathrm{No} ; \checkmark=$ Yes 
Table 5 Table of findings by TDF domain

\begin{tabular}{|c|c|c|c|c|}
\hline Target clinical behaviour & TDF domain & Reported barrier & Reported enabler & $\begin{array}{l}\text { Behaviour change technique } \\
\text { label }\end{array}$ \\
\hline \multirow[t]{5}{*}{ Swallow assessment } & $\begin{array}{l}\text { Environmental context } \\
\text { and resources }\end{array}$ & $\begin{array}{l}\text { - Difficulty finding time to document } \\
\text { screening results in the electronic } \\
\text { health record [24] }\end{array}$ & $\begin{array}{l}\text { - Efficient processes to support swallow screen } \\
\text { tool administration and interpretation [24] }\end{array}$ & $\begin{array}{l}\text { - Restructuring the physical } \\
\text { environment }\end{array}$ \\
\hline & Social influences & - No data available & $\begin{array}{l}\text { - Multidisciplinary team cooperation and } \\
\text { support from ED administrators [24] }\end{array}$ & - Social support (unspecified) \\
\hline & Knowledge & - No data available & $\begin{array}{l}\text { - More education on dysphagia and evidence- } \\
\text { based screening of swallowing [24] }\end{array}$ & $\begin{array}{l}\text { - Information about health } \\
\text { consequences }\end{array}$ \\
\hline & Skills & $\begin{array}{l}\text { - Inaccurate interpretation of screening } \\
\text { items [24] } \\
\text { - Inconsistent administration of the } \\
\text { swallow screen tool [24] }\end{array}$ & - No data available & - No data available \\
\hline & $\begin{array}{l}\text { Memory, attention and } \\
\text { decision processes }\end{array}$ & $\begin{array}{l}\text { - Difficulty recalling all screening items } \\
\text { during administration of the swallow } \\
\text { screen tool [24] }\end{array}$ & - No data available & - No data available \\
\hline \multirow[t]{3}{*}{$\begin{array}{l}\text { All patients to be assessed for } \\
\text { tPA eligibility } \\
\text { All eligible patients receive tPA }\end{array}$} & Beliefs about capabilities & - Lack of self-efficacy [27] & $\begin{array}{l}\text { - Informants emphasized that the rapid } \\
\text { expansion of stroke treatment options in } \\
\text { recent decades has contributed to work pride } \\
\text { and improved motivation to implement } \\
\text { guidelines [28] } \\
\text { - "I can" accurately identify stroke patients } \\
\text { (93.7\%) [25] } \\
\text { - "I can" accurately identify which stroke } \\
\text { patients may be eligible for tPA (62.0\%) [25] } \\
\text { - The hospital has a policy for the management } \\
\text { of stroke patients (85.8\%) [25] } \\
\text { - The hospital has a policy for rapid referral of } \\
\text { suspected stroke patients from ED to stroke } \\
\text { specialists (76.2\%) [25] } \\
\text { - The hospital has a policy for rapid access to } \\
\text { imaging for suspected stroke patients (87.0\%) } \\
\text { [25] } \\
\text { - The hospital has a policy for administration of } \\
\text { tPA when appropriate (72.7\%) [25] } \\
\text { - Exposure, mentoring, protocols and experience } \\
\text { through the implementation of stroke units } \\
\text { in rural facilities, telemedicine and stroke code } \\
\text { protocols might be beneficial to improve } \\
\text { physicians' ability to confidently diagnose } \\
\text { stroke patients eligible for tPA treatment [29] } \\
\text { - Confidently interpret brain imaging scans } \\
\text { (66.9\%) [25] }\end{array}$ & $\begin{array}{l}\text { - Social support (practical) } \\
\text { - Focus on past success } \\
\text { - Focus on past success } \\
\text { - Focus on past success } \\
\text { - Focus on past success } \\
\text { - Focus on past success } \\
\text { - Focus on past success } \\
\text { - Verbal persuasion about } \\
\text { capability; Focus on past } \\
\text { success; Exposure } \\
\text { - Focus on past success }\end{array}$ \\
\hline & Intentions & - Lack of motivation [27] & $\begin{array}{l}\text { - Taking active part in quality improvement and } \\
\text { research programs [28] }\end{array}$ & $\begin{array}{l}\text { - Restructuring the social } \\
\text { environment }{ }^{a}\end{array}$ \\
\hline & Knowledge & $\begin{array}{l}\text { - Lack of guideline awareness [27] } \\
\text { - Lack of guideline familiarity [27] }\end{array}$ & $\begin{array}{l}\text { - Guideline awareness and knowledge among } \\
\text { all staff [28] }\end{array}$ & $\begin{array}{l}\text { - Information about health } \\
\text { consequences }\end{array}$ \\
\hline
\end{tabular}

All patients to be assessed for tPA eligibility

All eligible patients receive tPA

consequences 
Table 5 Table of findings by TDF domain (Continued)

- Lack of knowledge about and experience with thrombolytic therapy [28]

Failure to react to guideline deviations [28]

Uncertainty with patient selection criteria [29]

Blood pressure control [26]

Environmental context and resources

Social/professional role and identity

Optimism

Behavioural regulation

- Lack of agreement between guidelines [27]

Stressful working conditions [28]

- Recruitment difficulties [28]

- Limited time, human, and financial

resources [28]

Duty schedule inhibiting training [28]

Lack of continuity (with various

dimensions) [28]

- Pre-hospital delays [29]

-Patients presenting outside the time window [26]

- ED delays [29]

- Long communication time between

ED staff and neurology

team [26]

- Delayed referral from GP [32]

Not ideal setting [29]

- Administrative barriers [29]

- Lack of urgency in the ED [26]

Beliefs about consequences - Lack of outcome expectancy [27]

- Old-fashioned views on stroke,

with low expectations of

therapeutic options [28]

Physician reluctance [26]

- Undue respect for treatment [28]

- Risk of intra-cranial haemorrhage [29]

- Uncertainty about benefits of tPA [29]

- Insufficient recognition by peers and decision makers [28]

- Poor professional identity [28]

- Formal power structures and prestige $[28]$

- Failure to react to guideline deviations [28]
Knowledge and attitudes of the providers on how to offer tPA to stroke patients [27]

Continuing professional education [28]

- Education on symptoms of stroke, tPA use,

pathways and protocols, its efficacy and ICH

risk [29]

- Education for physicians on the calculated risk

of ICH following intravenous tPA [29]

- Formal and informal meetings [28]

Short intra hospital distances for thrombolytic processes [28]

"To help me follow stroke care protocol" there are checklists/decision aids to help identify and triage a possible stroke case (68.8\%) [25]

- "To help me follow stroke care protocol" there are checklists/decision aids to help identify stroke patients eligible for tPA (66.7\%) [25]

"At all times I have immediate access to" advice

from a senior colleague in managing stroke

(76.9\%) [25]

- "I have immediate access to" staff trained to

interpret images (78.5\%) [25]

No data available

- Close collaboration with staff outside the stroke unit [28]

- Good leadership [28]

- Positive staff attitudes, within and outside the stroke unit [28]

Implementation work included in routines [28] - Feedback on success or failure [28]

- Quality assurance with continuous feedback on implementation progress [28]
- Information about health consequences

- Information about health

consequences

Information about health

consequences

- Information about health

consequences

Restructuring the social environment

Restructuring the physical

environment

Prompts/cues

Prompts/cues

Restructuring the physical

environment

- Restructuring the physical

environment

No data available

- Restructuring the physical environment $^{\mathrm{a}}$

-Social support (unspecified)

No corresponding technique ${ }^{b}$

- Habit formation ${ }^{a}$

Feedback on outcome(s) of

behaviour ${ }^{\mathrm{a}}$; Feedback on

behaviour $^{\text {a }}$ 
Table 5 Table of findings by TDF domain (Continued)

Triaged at Australian Triage Scale 1 or 2

Transfer
Skills

Social influences

- Lack of support $[28,29]$

Knowledge

Environmental context and resources

Skills

Social/professional role and identity

Beliefs about capabilities

- Interpretation of CT [29]

- Clinical diagnostic uncertainty [29]

- Personal stroke neurology

experience [29]

- Experience with TPA inclusions and

exclusions [29]

Difficulty identifying stroke in

presenting patients [26]

Inadequate public education about stroke: including patients and GPs [30] - Stroke not recognised as a priority [31]

- Lack of resource : staff shortages in facilities [30]

- Competing demands in ED and staffing challenges during busy times [31] information [30]

- Lack of coordination between staff [30]

- Overlong waiting times - stroke care examinations [30]

- Lack of comfort with assessing stroke patients using the National Institutes of Health Stroke Scale [31]

Environmental context

and resources centre [32]
Lack of training and public

- Exposure and experience through the

implementation of stroke units in rural facilities,

telemedicine and stroke code in rotocols might,

be beneficial to improve physicians' ability to

confidently diagnose stroke patients eligible for

tPA treatment [29]

Continuing professional education [28]

- "I regularly" treat acute stroke patients

(91.4\%) [25]

"I regularly" have the opportunity to treat stroke cases of varying complexity (88.3\%) [25]

Trained stroke nurses available [25]

- "I have seen" tPA administered to stroke patients on several occasions (78.8\%) [25]

- Involvement of all professionals in implementation work [28]

Respected and influential members of this

hospital endorse the use of tPA (67.5\%) [25]

- Between-hospital benchmarking and sharing

experiences with staff at other hospitals [28]

No data available

- Having the stroke protocol for consistency [31]

- No data available

- No data available

No data available

- No data available
No data available

No data available

No data available

- Feedback on outcome(s) of behaviour ${ }^{\mathrm{a}}$; Feedback on

behaviour $^{a}$

- Behavioural practice/rehearsal - Instruction on how to perform a behaviour ${ }^{\mathrm{a}}$

- Behavioural practice/rehearsal

- Behavioural practice/rehearsal

Restructuring the physical

Demonstration of the behavior

- Social support (unspecified)

- Information about others

approval

Social comparison

No data available

Prompts/cues

- No data available

\section{CT Computed tomography, ED Emergency departments, ICH Intracerebral Haemorrhage}

${ }^{\text {a } T h i s ~ t e c h n i q u e ~ w a s ~ n o t ~ s u g g e s t e d ~ b y ~ t h e ~ C a n e ~ e t ~ a l . ~ m a t r i x ~ f o r ~ t h e ~ c o r r e s p o n d i n g ~ d o m a i n ~}$

It was agreed that there was no behaviour change technique that represented this enabler. This is possibly due to the limited reporting of how the staff were influenced to develop the positive attitudes 
guidelines [28]. The barriers identified by Williams et al. related more to procedural knowledge such as uncertainty with respect to the patient selection criteria for tPA [29]. More specifically, in one study staff (ED nurses and pharmacists) reported that physicians wait until towards the end of the tPA treatment time window to see whether patients' symptoms improve before committing to tPA, thus delaying time to tPA treatment and potentially lowering tPA treatment rates [26]. Education to provide knowledge about how to offer tPA [27], identification of stroke [25] and interpretation of brain imaging scans was reported as an enabler [25]. Correspondingly, lack of education on symptoms of stroke, tPA use, and lack of pathways and protocols were reported as significant barriers by Williams et al. [29]. More education around dysphagia and evidence-based screening of swallowing post stroke was identified as an enabler by the only study investigating the swallow care behaviours [24].

\section{Skills}

Lack of skills was reported in relation to the triage, tPA and swallow care behaviours, but not for the transfer behaviours. Staff reported that a lack of practice and skills development were barriers to administrating tPA, particularly with regards to interpretation of computed tomography scans, clinical diagnostic uncertainty and individual experience in stroke neurology [29]. In one study, the administration and inaccurate interpretation of swallow screening items were reported [24].

\section{Social/professional role and Identity}

Social/professional role and identity related issues were reported for the triage and the tPA-related behaviours. A lack of a dedicated nurse to manage stroke patients was reported in one study [26]. Limited social identity, i.e., insufficient recognition by peers and decision makers were barriers to delivering the tPA-related behaviours [28].

\section{Beliefs about capabilities}

Data relating to beliefs about capabilities were only reported for the tPA-related behaviours. Barriers relating to this domain included a lack of self-efficacy and motivation [27]. A number of similar enablers, were found in two studies and included experience and exposure of "telemedicine and stroke code protocols", which were focused on improving physician's ability to confidently diagnose stroke patients eligible for tPA treatment [29]. Similarly, Grady et al. reported that the majority of survey participants believed that being able to "confidently interpret brain imaging scans" was an enabling factor [25].

\section{Optimism}

Data were only reported for the tPA-related behaviours and relevant enablers reported by staff included positive staff attitudes within and outside the stroke unit [28].

\section{Beliefs about consequences}

Data were only reported for tPA-related behaviours. In three studies staff beliefs indicated belief in a lack of positive outcome for patients after tPA [27-29] including that staff held "old-fashioned views" about the lack of benefit of tPA for improving outcomes after stroke [28]. Reluctance of staff to administer tPA was reported (participants were ED nurses and ED pharmacists) in one study as a barrier and this was likely to be due to poorly understood beliefs about the benefits of using tPA [26].

\section{Intentions}

Data were only reported for the tPA related care elements. Lack of motivation was the only barrier reported which related to this TDF domain [27].

\section{Memory, attention, and decision process}

Data were only reported for the swallow assessment behaviours. The only factor relating to this domain was staff reporting difficulty recalling all screening items during administration of a swallow screen [24].

\section{Environmental context and resources}

All care elements apart from the management of blood glucose levels and the management of fever had information reported on environmental context and resources. Working with a busy environment with competing demands was a frequently reported barrier for the appropriate triage of patients with stroke. Barriers were largely related to delays and were often categorised as pre-hospital clinical care, in-hospital clinical care and/or administrative to the successful assessment for and delivery of tPA [26, 29]. Communication between departments was believed to play a pivotal role in the success of delivering tPA [26]. Financial resources were reported as a potential barrier in one study, without further specification [31], but in another, no respondents rated cost as a significant barrier [28]. Stecksen et al. identified stressful working conditions, limited time, and lack of continuity as other barriers to assessing patients for suitability for IPA and delivering tPA treatment [28]. In relation to rapid transfer of stroke patients from the ED to the stroke unit, the two barriers reported related to poor patient flow to the appropriate ward [32]. A stroke protocol was the only enabler that was reported in relation to facilitating appropriate triage [31], and similarly, efficient processes was one of the three 
enabling factors reported to assist in the implementation of a swallow screen tool [24].

\section{Social influences}

Social influences were reported in relation to the swallow and tPA related behaviours. A lack of support was reported as a barrier in two studies in relation to the tPA elements [28, 29]. Enablers associated with social influences included sharing of experiences amongst staff [28], the endorsement of the use of tPA [25], and advice from a senior colleague [25]. Social support provided from administrators and the wider multidisciplinary team was perceived by nurses as factors which would assist the uptake of swallow screening practices in ED [24].

\section{Behaviour regulation}

Data were only reported for the tPA-related behaviours. One reported enabler relevant to this domain was initiation of an assurance mechanism with continuous feedback on success or otherwise of implementation [28].

No authors attempted to interpret the data using an existing behaviour change theory, framework, or model. A purposefully developed taxonomy was used in one study to classify barriers [27], whilst in one other study enablers were classified into behaviour change domains; however, the framework, model or theory that underpinned these domains was not disclosed [25]. A summary of the TDF domains as represented by the barriers and enablers reported in the studies is shown in Table 6.

\section{The allocation of BCT labels to reported enablers}

The total number of BCTs assigned was 18. The BCTs most frequently assigned to the reported enablers were 'focus on past success' $(n=8)$ and 'information about health consequences' $(n=5)$. There were three occasions where more than one technique was considered to align with a reported enabler. No technique was aligned with the reported enabler "positive staff attitudes, within and outside the stroke unit" as the underlying meaning was not clear and no other contextual data was provided in the study. The aligning behaviour change techniques for each reported enabler are provided in Table 5.

\section{Discussion}

This study produced new knowledge on the barriers and enablers for the delivery of key evidence-based protocols in an emergency setting and interpreted within a relevant theoretical framework. Barriers and/or enablers were identified for triage, thrombolysis, swallow assessment and patient transfer related clinical behaviours. Barriers relating the environmental context and resources domain such as a lack of time, stressful working conditions and ED delays were common to all four behaviours. Barriers relating to the skills domain such as inconsistent administration of swallow screen tools, and to the memory, attention, and decision processes domain such as difficulty recalling screening items during administration were relevant to only one clinical behaviour. There were no studies which identified barriers or enablers with regards to two of the six target behaviours: monitoring and management of (1) temperature and (2) blood glucose levels. There were no barriers or enablers

Table 6 Barriers and enablers classified by TDF domain by target clinical behaviour

\begin{tabular}{|c|c|c|c|c|c|c|c|c|c|c|c|c|}
\hline \multirow[t]{2}{*}{ TDF Domain } & \multicolumn{2}{|l|}{ Triage } & \multicolumn{2}{|c|}{ Thrombolysis } & \multicolumn{2}{|c|}{ Fever } & \multicolumn{2}{|c|}{ Glucose } & \multicolumn{2}{|l|}{ Swallow } & \multicolumn{2}{|l|}{ Transfer } \\
\hline & $B\left(n^{a}=1\right)$ & $E(n=1)$ & $B(n=6)$ & $E(n=4)$ & B & $\mathrm{E}$ & $\mathrm{B}$ & $E$ & $B(n=1)$ & $E(n=1)$ & $B(n=1)$ & $E(n=1)$ \\
\hline \multicolumn{13}{|l|}{ Knowledge } \\
\hline \multicolumn{13}{|l|}{ Skills } \\
\hline \multicolumn{13}{|c|}{ Social/Professional Role \& Identity } \\
\hline \multicolumn{13}{|l|}{ Beliefs about Capabilities } \\
\hline \multicolumn{13}{|l|}{ Optimism } \\
\hline \multicolumn{13}{|c|}{ Beliefs about Consequences } \\
\hline \multicolumn{13}{|l|}{ Reinforcement } \\
\hline \multicolumn{13}{|l|}{ Intentions } \\
\hline \multicolumn{13}{|l|}{ Goals } \\
\hline \multicolumn{13}{|c|}{ Memory, Attention \& Decision Processes } \\
\hline \multicolumn{13}{|c|}{ Environmental Context \& Resources } \\
\hline \multicolumn{13}{|l|}{ Social influences } \\
\hline \multicolumn{13}{|l|}{ Emotion } \\
\hline Behavioural Regulation & & & & & & & & & & & & \\
\hline
\end{tabular}

${ }^{a}$ Number of studies. $B$ Barriers, $E$ Enablers. Note: no studies were identified which addressed the care elements relating to temperature and blood glucose level monitoring and management 
derived from the systematic review findings that could not be accounted for by one of the TDF domains, indicating that this framework is highly relevant to behaviour change within this clinical context.

The use of the TDF has allowed the comprehensive identification of barriers and enablers for areas such as these where existing evidence is lacking. This process has identified several domains of the TDF where no primary barriers or enablers were identified in the included studies: reinforcement, goals, and emotion. As significant emotional issues such as excessive fear of harm and complications have been identified in other literature $[37,38]$ regarding thrombolysis in stroke, this emphasises that there remain gaps the published literature where barriers and enablers have not been reported. Evidence suggests that individuals find it more difficult to verbalise their affective attitudes (i.e., emotions) [39]. The TDF has been found to elicit emotion related barriers to behaviour change more effectively than atheoretical approaches to identifying barriers [7].

Interestingly, only one included study subsequently used the data from a barrier and enabler assessment to develop an implementation intervention (a dysphagia screening bundle) [24]. The evaluation revealed that swallowing screening practices significantly improved after the implementation of this bundle; however, the author did not state whether this could be attributed to the information yielded by the barrier assessment. Indeed, the findings from this systematic review have since been used to inform the development of an implementation intervention for an ongoing trial (the $\mathrm{T}^{3}$ trial) to target these clinical behaviours in an ED setting. The $\mathrm{T}^{3}$ trial investigators aim to evaluate the supported implementation of key best practice acute stroke care clinical elements relating to the appropriate triage, treatment with tPA, management and monitoring of blood glucose levels, temperature and of swallowing difficulties, and transfer from ED to the ASU.

Although barriers and enablers are often hypothesised to be determinants of behaviour, their actual influence on performing a certain practice has been questioned as other contextual factors may play more significant roles [40]. The large number of barriers and enablers within the environmental context and resources domain highlight the importance of health system environments. A broader health systems approach has been used to investigate the association between health system factors such as urban location and tPA treatment rates [41]. Paul et al. concluded that to improve tPA treatment rates, specific health system factors need to be targeted.

\section{Limitations}

There were few studies that met the inclusion criteria for this review included in this review, most likely due to the limited published literature in this field. Due to the limitation of subject headings for the terms "barriers" and "enablers," electronic indexing synonyms were used for key words to ensure the search was sensitive; however, this may have compromised the precision of the search and as for other reviews of barriers and enablers in healthcare there is potential for studies not to be identified [42]. The quality of the included studies was comprised by small sample sizes for the quantitative studies and the limited reporting and/or lack of robust sampling techniques. The different approaches used to analyse the qualitative and quantitative data within the included studies posed challenges for data extraction. For example, some of the studies referred to stroke care in general, making it difficult to ascertain which barriers related to each of the target clinical behaviours. The use of the TDF for secondary analysis required some subjective interpretation due to the lack of contextual detail reported for some of the barriers and enablers. This limitation has been reported by other authors [21]. No included study used a behaviour change theory, standard taxonomy, or framework to interpret findings.

Researchers have reported that barriers can be represented by more than one domain and have also acknowledged the complex relationship between domains [21]. In this study this was evident when attempting to interpret and map the barriers to the framework with often limited contextual information. For example, "inaccurate interpretation of screening items" in performing a swallow screen was mapped to skills as the primary TDF domain but may also be related to the TDF domain memory, attention, decision processes. In this study, we agreed and reported the primary domain only. Further, research is required to guide how best to select a theoretical domain in these instances, e.g., what process should be taken to identify which of two (or more) domains primarily represents a specific barrier.

There were instances whereby the BCT used in the enabling strategy reported in the included studies did not align with the BCTs that the Cane et al. matrix recommends for use to target domains. For example, the BCTs used in the enabling strategies (habit formation; feedback on outcome of behaviour; feedback on behaviour) for the behavioural regulation domain do not align with the $\mathrm{BCT}$ recommended by the Cane et al. matrix (self-monitoring of behaviour). This indicates that Cane et al. matrix is a useful, but not comprehensive tool to identify appropriate enabling strategies. It is likely that the discrepancies are due to individual contextual factors, not accounted for by the matrix; highlighting the ongoing importance of local barrier and enabler assessments for any implementation strategy. 


\section{Strengths}

Both qualitative and quantitative primary studies were focused on capturing barriers and enablers as reported by healthcare professionals. This provides novel data in comparison to existing reviews in this area which often relied on observational or registry data to characterise barriers, i.e., investigate causes or consequences of pre-determined factors such as in-hospital delays. The review processes used were robust and transparent adhering to the Preferred Reporting Items for Systematic Reviews and MetaAnalyses (PRISMA) standard. The search strategy underwent extensive review and iteration to ensure efficiency and accuracy in the conduct and output of the search. The data collection process was conducted in duplicate and decisions were cross-checked with another researcher.

The use of the TDF in systematic reviews is an emerging methodology and has only been applied in a few recent studies. The assignment of BCTs to barriers was not conducted as part of this review as the information was not available in the individual studies. However, one potential application of the barrier data is to select; using a panel of experts for example, the most appropriate behaviour change techniques to address the barriers to further inform the $\mathrm{T}^{3}$ trial implementation intervention development. For example, one of the BCTs recommended by the mapping conducted by Cane et al. [18] to overcome barriers classified within the skills domain is behavioural practice/rehearsal [35]. The enabler data from this review could then be applied to inform how this technique can be feasibly employed in clinical practice. For example, the enabler "giving physicians the opportunity to treat stroke cases of varying complexity" could be viewed as a deliverable form of this technique. This approach has been successfully used to develop an implementation intervention to improve the management of traumatic brain injury in the ED [43]. Furthermore, classifying the enablers to the best aligning $\mathrm{BCT}$ enhances the reportability and transferability of findings in this process.

\section{Area of future research}

The authors of one survey presented and analysed the data by decision makers and non-decision makers and revealed significant difference between the two groups [25]. Therefore, it may be important to further identify and explore the differences and similarities in perceptions between different disciplines, especially when implementing a multidisciplinary intervention. It would be worthy to further investigate whether the barriers identified by the review could be feasibly addressed, possibly by devising a panel of experts to make this judgment. If the barrier is deemed non-modifiable, then it is not likely to be a feasible target for an implementation intervention. The monitoring of barrier status during the implementation of an intervention would provide evidence for the types of barriers that can easily be overcome, the type of barriers which may be intractable and the effectiveness of particular BCT directed at barriers/ enablers within various theoretical domains. Currently, mapping of BCTs to the TDF domains is largely based on expert opinion and a more robust higher level of evidence is required. There also needs to be more illustrations of how barrier and/or enabler data has been used to develop implementation interventions. Consistent use of a theoretical framework will assist with progressing this work by enabling meaningful compilation of evidence from a variety of sources. In addition, none of the studies reported monitoring the status of barriers over time or conducted a pre-and post implementation barrier assessment. Such design would add significant weight to the evidence regarding the value of barrier and enabler assessment, and subsequent use to target interventions.

Gaining patient's and family member's perceptions of stroke care in the ED were not considered by any of the studies and in the context of shared-decision making is an area that warrants further research. Patient and family preferences for and against practices such as tPA [44] and "nil by mouth" [45] has the potential to impact on the implementation of certain practices.

\section{Conclusion}

Barriers and/or enablers have been identified for the majority of the target clinical behaviours which could be used to inform barrier and enabler assessments in similar acute settings. Due to the likely gaps in the evidence base, barrier, and enabler data for some of the clinical behaviours and within some of the theoretical domains, could not be identified. The novel assignment of BCT labels to reported enablers will allow researchers and clinicians to use and potentially modify these techniques to deliver these important clinical behaviours in routine practice. When considering the findings from reviews of barriers and enablers, it is recommended that a reporting framework as illustrated in this paper should be adopted. This would facilitate the comparison, contrasting, and synthesis of barrier and/or enabler data within a consistent context framework and facilitate recognition identification of proven strategies to address such barriers [19].

\section{Appendix \\ Search Strategies \\ OVID Medline}

1. exp cerebrovascular disorders/or exp basal ganglia cerebrovascular disease/

2. exp basal ganglia hemorrhage/or exp brain ischemia/

3. exp brain infarction/or exp brain stem infarctions/ 
4. exp cerebral infarction/or exp infarction, anterior cerebral artery/

5. exp infarction, middle cerebral artery/

6. exp infarction, posterior cerebral artery/

7. exp hypoxia-ischemia, brain/

8. exp "intracranial embolism and thrombosis"/

9. exp intracranial hemorrhages/

10.exp cerebral hemorrhage/

11.exp subarachnoid hemorrhage/or stroke/

12.exp Health Plan Implementation/

13." "Diffusion of Innovation"/

14.((implementation or implementing) and (care or healthcare)).ti.

15.((effect? or effectiveness or chang\$ or improv\$ or impact) adj3 practice).ti.

16.(Improv\$ adj3 (diagnosis or treatment? or prescribing)).ti.

17.Evidence-Based Practice/

18.(((evidence or evidence-based) adj4 intervention) or evidence-driven).ti,ab.

19.((knowledge adj2 (application or broke\$ or creation or diffus\$ or disseminat\$ or exchang\$

or implement\$ or management or mobili\$ or translat\$ or transfer\$ or uptake or utili\$))

or (evidence\$ adj2 (exchang\$ or translat\$

or transfer\$))).ti.

20."Quality of Health Care"/

21."Delivery of Health Care/st [Standards]

22." Treatment Outcome/

23."Continuity of Patient Care"/

24.(determin\$ or facilitate\$ or barrier\$ or enabler\$).ti.

25.(evidence\$ adj2 (barrier\$ or enabler\$ or enabler\$ or uptake\$ or utilis\$ or utiliz\$ or diffus\$ or disseminat\$)).tw.

26.((information or evidence) adj2 uptake).ti.

27.(research adj2 (barrier\$ or enabler\$ or enabler\$ or uptake $\$$ or utilis\$ or utiliz\$ or diffus\$ or disseminat\$)).tw.

28.(information adj2 (barrier\$ or enabler\$ or enabler\$ or uptake\$ or utilis\$ or utiliz\$ or diffus\$ or disseminat\$)).tw.

29. (data adj2 (barrier\$ or enabler\$ or enabler\$ or uptake\$ or utilis\$ or utiliz\$ or diffus\$ or disseminat\$)).tw.

30.Health Services Accessibility/

31. "Critical Pathways/og [Organization \& Administration]

32.Clinical Protocols/

33.Models, Organizational/

34.exp triage/

35.exp delegation, professional/

36.(stroke adj3 (unit or units or ward or wards or hospital or hospitals or centre\$ or team or teams)).tw. 37.("early transfer" or "early referral”).ti.

38.Decision Making/

39.Early Diagnosis/

40.Emergency Nursing/

41."Stroke/di [Diagnosis]

42." Stroke/nu [Nursing]

43." Stroke/dt [Drug Therapy]

44.Emergency Service, Hospital/og [Organization \& Administration]

45."Time Factors/

46.exp Tissue Plasminogen Activator/

47.exp thrombolytic therapy/

48.exp fibrinolytic agents/or plasmin/or plasminogen/ or tissue plasminogen activator/

49.((clot\$ or thrombus) adj5 (lyse or lysis or dissolve\$ or dissolution)).ti,ab.

50.(tPA or t-PA or rtPA or thrombolysis or plasminogen or plasmin or alteplase or actilyse).ti,ab.

51.(anistreplase or streptodornase or streptokinase or urokinase or pro? urokinase or rpro?uk or lumbrokinase or duteplase or lanoteplase or pamiteplase or reteplase or saruplase or staphylokinase or streptase or tenecteplase or desmoteplase or retevase).tw.

52.exp fever/

53.(fever or temperature or hyperthermia or pyrexia).tw.

54.exp Blood Glucose/

55.Hyperglycemia/di [Diagnosis]

56.Hyperglycemia/dt [Drug Therapy]

57."Hyperglycemia/th [Therapy]

58.Hypoglycemic Agents/ae [Adverse Effects]

59.Hypoglycemic Agents/tu [Therapeutic Use]

60."Monitoring, Physiologic/nu [Nursing]

61.exp insulins/or insulin infusion systems/

62."Deglutition Disorders/

63.(swallow\$ or dysphagia).ti.

64.13 or 14 or 15 or 16 or 17 or 18 or 19 or 20 or 21 or 22 or 23 or 24 or 25 or 26 or 27 or 28 or 29

65.1 or 2 or 3 or 4 or 5 or 6 or 7 or 8 or 9 or 10 or 11

66.12 or 13 or 14 or 15 or 16 or 17 or 18 or 19 or 20 or 21 or 22 or 23 or 24 or 25 or 26 or 27 or 28 or 29

67.30 or 31 or 32 or 33 or 34 or 35 or 38 or 39 or 40 or 41 or 42 or 43 or 44 or 45 or 46 or 47 or 48 or 49 or 58 or 51 or 52 or 53 or 54 or 55 or 56 or 57 or 58 or 59 or 60 or 61 or 62 or 63

68.66 and 67 and 68

69.Letter/or Comment/or Editorial/

70.69 not 70 


\section{OVID EMBASE Search Strategy}

1. exp clinical pathway/

2. ((implementation or implementing) and (care or healthcare)).ti.

3. ( (effect? or effectiveness or chang\$ or improv\$ or impact) adj3 (practice or organisation $\$)$ ).ti.

4. (Improv\$ adj3 (diagnosis or treatment?)).ti.

5. "evidence based practice/

6. (((evidence or evidence-based) adj4 intervention) or evidence-driven).ti.

7. ((knowledge adj2 (application or broke\$ or creation or diffus\$ or disseminat\$ or exchang\$ or implement\$ or management or mobili\$ or translat\$ or transfer\$ or uptake or utili\$)) or (evidence\$ adj2 (exchang\$ or translat\$ or transfer\$))).ti.

8. "health care delivery/

9. "Treatment Outcome/

10. "Continuity of Patient Care"/

11.(evidence\$ adj2 (barrier\$ or enabler\$ or enabler\$ or uptake\$ or utilis\$ or utiliz\$ or diffus\$ or disseminat\$)).tw.

12.((information or evidence or implement\$) adj2 (uptake or determin\$ or enabler\$ or barrier\$ or enabler\$)).ti,ab.

13.(research adj2 (barrier\$ or enabler\$ or enabler\$ or uptake\$ or utilis\$ or utiliz\$ or diffus\$ or disseminat\$)).tw.

14.(information adj2 (barrier\$ or enabler\$ or enabler\$ or uptake\$ or utilis\$ or utiliz\$ or diffus\$ or disseminat\$)).tw.

15.(data adj2 (barrier\$ or enabler\$ or enabler\$ or uptake $\$$ or utilis\$ or utiliz\$ or diffus\$ or disseminat\$)).tw.

16.exp triage/

17.exp delegation, professional/

18.(stroke adj3 (unit or units or ward or wards or hospital or hospitals or centre\$ or team or teams)).tw.

19.("early transfer" or "early referral").ti.

20.Decision Making/

21.Early Diagnosis/

22.Emergency Nursing/

23.stroke/di, dt, th [Diagnosis, Drug Therapy, Therapy]

24.emergency health service/

25."time/

26.Tissue Plasminogen Activator/

27.exp thrombolytic therapy/

28.exp fibrinolytic agents/or plasmin/or plasminogen/ or tissue plasminogen activator/

29.((clot\$ or thrombus) adj5 (lyse or lysis or dissolve\$ or dissolution)).tw.
30.(tPA or t-PA or rtPA or thrombolysis or plasminogen or plasmin or alteplase or actilyse).tw.

31.(anistreplase or streptodornase or streptokinase or urokinase or pro? urokinase or rpro?uk or lumbrokinase or duteplase or lanoteplase or pamiteplase or reteplase or saruplase or staphylokinase or streptase or tenecteplase or desmoteplase or retevase).tw.

32.fever/

33.(fever or temperature or hyperthermia or pyrexia).ti.

34.exp Blood Glucose/

35.hyperglycemia/di, dt, rh, si [Diagnosis, Drug Therapy, Rehabilitation, Side Effect]

36.antidiabetic agent/ae, th [Adverse Drug Reaction, Therapy]

37.insulin derivative/

38.dysphagia/

39.(swallow\$ or dysphagia).ti.

40.exp cerebrovascular disorders/

41.((cerebral* or cerebellar or brainstem or vertebrobasilar or stroke) adj5 (infarct" or ischaemi" or ischemi" or thrombo" or emboli* or apoplexy)).tw.

42.exp hemiplegia/

43.(hemipleg* or hemipar* or paresis or paretic).tw.

44.(stroke or poststroke or post-stroke or cva* or cerebral vascular accident" ${ }^{*}$ or cerebrovascular accident*).tw.

45.((cerebral or brain or subarachnoid) adj5 (haemorrhage* or hemorrhage* or haematoma* or hematoma* or bleed*)).tw.

46.1 or 2 or 3 or 4 or 5 or 6 or 7 or 8 or 9 or 10 or 11 or 12 or 13 or 14 or 15

47.16 or 17 or 20 or 21 or 22 or 23 or 24 or 25 or 26 or 27 or 28 or 29 or 30 or 31 or 32 or 33 or 34 or 35 or 36 or 37 or 38 or 39

48.40 or 41 or 42 or 43 or 44 or 45

49.46 and 47 and 48

50.Letter/or Editorial/

51.49 not 50

\section{CINHAL}

S1 (MH "Cerebrovascular Disorders") OR (MH "Basal Ganglia Cerebrovascular Disease+") OR (MH "Carotid Artery Diseases+") OR (MH "Cerebral Ischemia+") OR (MH "Cerebral Vasospasm") OR (MH "Intracranial Arterial Diseases+") OR (MH "Intracranial Embolism and Thrombosis") OR (MH "Intracranial Hemorrhage+") OR (MH "Stroke") OR (MH "Vertebral Artery Dissections")

S2 (MH "Stroke Patients")

S3 TI (stroke or cerebrovasc" or brain vasc" or cerebral vasc* or cva* or apoplex*) or $\mathrm{AB}$ (stroke or 
cerebrovasc* or brain vasc* or cerebral vasc* or cva* or apoplex*)

S4 TI (brain* or cerebr* or cerebell* or vertebrobasilar or hemispher* or intracran* or intracerebral or infratentorial or supratentorial or MCA or anterior circulation or posterior circulation or basal ganglia) or $\mathrm{AB}$ (brain* or cerebr* or cerebell* or vertebrobasilar or hemispher* or intracran* or intracerebral or infratentorial or supratentorial or MCA or anterior circulation or posterior circulation or basal ganglia)

S5 TI (ischemi* or ischaemi* or infarct* or thrombo* or emboli*) or $\mathrm{AB}$ (ischemi* or ischaemi* or infarct* or thrombo* or emboli*)

S6 TI (brain brain* or cerebr" or cerebell* or intracerebral or intracran* or parenchymal or intraventricular or infratentorial or supratentorial or basal gangli*) or AB (brain* or cerebr* or cerebell* or intracerebral or intracran* or parenchymal or intraventricular or infratentorial or supratentorial or basal gangli*)

S7 TI (haemorrhage* or hemorrhage* or haematoma* or hematoma* or bleed*) or AB (haemorrhage* or hemorrhage* or haematoma* or hematoma* or bleed*)

S8 MJ implementing

S9 TI (uptake or determine\$ or enabler\$ or enable\$ or barrier\$)

S10S8 OR S9

S11 S1 OR S2 OR S3

S12 S4 AND S5

S13 S6 AND S7

S14 S11 OR S12 OR S13

S15 S15 AND S10

\section{Web of Science}

1. $\mathrm{TS}=$ (stroke or cva or "cerebral vascular" or cerebrovascular)

2. $\mathrm{TI}=$ (information $\mathrm{OR}$ evidence $\mathrm{OR}$ implement*)

3. $\mathrm{TI}=$ (uptake or determin $\$$ or enabler\$ or enable\$ or barrier\$)

4. \#2 and \#3

5. \#1 AND \#4

\section{Abbreviations}

ASU: Acute stroke unit; ED: Emergency Departments; $T^{3}$ : Triage, Treatment and transfer; TDF: Theoretical domains framework; tPA: Thrombolysis

\section{Acknowledgements}

Daun Jung conducted the hand searching and searching of grey literature during her Undergraduate Research Internship program at the Nursing Research Institute. DC was supported by a fellowship from the National Health and Medical Research Council (NHMRC; 1063761 co-funded by National Heart Foundation).

\section{Funding}

The $T^{3}$ trial (registry number is ACTRN12614000939695) is funded by the National Health Medical Research Council ID APP1024812. This project was supported by an infrastructure grant provided by the Australian Catholic University to support the International Stroke Research Collaboration (ISReC).

\section{Availability of data and materials \\ Not applicable.}

\section{Authors' contributions}

LC conducted the systematic review which involved developing the search strategies, running the searches in the databases and screening of references. EM and SM extracted data from a sub-set of included papers. Decisions were cross-checked with EM and SM at both the screening for exclusion, data extraction, and critical appraisal stages. LC and NT classified the barriers and enablers to the relevant domains of the TDF. LC wrote the first draft of the paper with contributions from EM, NT, RG, DC, JC, and SM. All authors read and approved the final manuscript.

\section{Competing interests}

The authors declare that they have no competing interests.

\section{Consent for publication}

Not applicable.

Ethics approval and consent to participate Not applicable.

\section{Author details}

${ }^{1}$ Nursing Research Institute, St Vincent's Health Australia (Sydney) and Australian Catholic University, Sydney, NSW, Australia. ${ }^{2}$ Centre for Healthcare Resilience and Implementation Science, Australian Institute of Health Innovation, Macquarie University, Sydney, NSW, Australia. ${ }^{3}$ Sunshine Coast Hospital and Health Service/Sunshine Coast Clinical School, The University of Queensland, Nambour, QLD, Australia. ${ }^{4}$ Translational Public Health and

Evaluation Division, Stroke and Ageing Research, School of Clinical Sciences at Monash Health, Monash University, Clayton, VIC, Australia. ${ }^{5}$ Public Health: Stroke Division, Florey Institute of Neuroscience and Mental Health, University of Melbourne, Parkville, VIC, Australia. ${ }^{6}$ Deakin University, Geelong, VIC, Australia. ${ }^{7}$ Eastern Health - Deakin University Nursing and Midwifery Research Centre, Box Hill, VIC, Australia.

Received: 18 May 2016 Accepted: 18 November 2016 Published online: 28 November 2016

\section{References}

1. National Stroke Foundation. Clinical Guideline for Stroke Management. 2010

2. American Heart Association. Get With The Guidelines ${ }^{\oplus}$-Stroke Overview. http://www.heart.org/HEARTORG/HealthcareResearch/ GetWithTheGuidelines/Get-With-The-Guidelines-Stroke_UCM_306098_ SubHomePage.jsp\#. Last accessed 15 Dec 2015

3. American Heart Association. FACTS. Preventable. Treatable. Beatable: Stroke in the United States. USA: AHA; 2013

4. Royal College of Physicians. Clinical Effectiveness and Evaluation Unit on behalf of the Intercollegiate Stroke Working Party. Clinical Audit Jan- March. UK: Sentinel Stroke National Audit Programme (SSNAP); 2014.

5. Romano JG, Muller N, Merino JG, Forteza AM, Koch S, Rabinstein AA. In-hospital delays to stroke tPA: paradoxical effect of early arrival. Neurol Res. 2007; doi: http://dx.doi.org/10.1179/016164107X240035

6. Grol R, Grimshaw J. From best evidence to best practice: effective implementation of change in patients' care. Lancet. 2003;362:1225-30.

7. Dyson J, Lawton R, Jackson C, Cheater F. Development of a theory-based instrument to identify barriers and levers to best hand hygiene practice among healthcare practitioners. Implement Sci. 2013:8:111.

8. Carter-Jones CR. Stroke tPA: Barriers to implementation. Int Emerg Nurs. 2011; doi: http://dx.doi.org/10.1016/j.ienj.2010.02.005

9. Eissa A, Krass I, Bajorek BV. Barriers to the utilization of thrombolysis for acute ischaemic stroke. J Clin Pharm Ther. 2012;37(4):399-409. doi:http://dx.doi.org/10.1111/j.1365-2710.2011.01329.x. 
10. Szoeke CE, Parsons MW, Butcher KS, Baird TA, Mitchell PJ, Fox SE, et al. Acute stroke tPA with intravenous tissue plasminogen activator in an Australian tertiary hospital. Med J Aust. 2003;178:324-8.

11. Lau AYL, Soo YOY, Graham CA, Woo WK, Wong EHC, Leung $H$, et al. An expedited stroke triage pathway: The key to shortening the doorto-needle time in delivery of tPA. Hong Kong Med. 2010;16:455-62.

12. Improved Clinical Effectiveness through Behavioural Research G. Designing theoretically-informed implementation interventions. Implement Sci. 2006;1:4. doi:10.1186/1748-5908-1-4.

13. Eccles M, Grimshaw J, Walker A, Johnston M, Pitts N. Changing the behavior of healthcare professionals: the use of theory in promoting the uptake of research findings. J Clin Epidemiol. 2005;58(2):107-12.

14. Michie S, Johnston M, Abraham C, Lawton R, Parker D, Walker A, et al. Making psychological theory useful for implementing evidence based practice: a consensus approach. Qual Saf Health Care. 2005;14(1):26-33.

15. Medical Research Council. A framework for development and evaluation of RCTs for Complex Interventions to improve Health. 2000. Available from: http://www.mrc.ac.uk

16. French SD, Green SE, O'Connor DA, McKenzie JE, Francis JJ, Michie S, et al. Developing theory-informed behaviour change interventions to implement evidence into practice: a systematic approach using the Theoretical Domains Framework. Implement Sci. 2012;7:38.

17. Taylor N, Conner M, Lawton R. The impact of theory on the effectiveness of worksite physical activity interventions: a meta-analysis and meta-regression. Health Psychology Review. 2012;6(1):33-73. doi:10.1080/17437199.2010. 533441.

18. Cane J, O'Connor D, Michie S. Validation of the theoretical domains framework for use in behaviour change and implementation research. Implement Sci. 2012;7(1):37.

19. Michie S, Johnston M, Francis J, Hardeman W, Eccles M. From theory to intervention: mapping theoretically derived behavioural determinants to behaviour change techniques. Appl Psychol. 2008;57(4):660-80. doi:10.1111/j.1464-0597.2008.00341.x

20. Wilkinson SA, McCray S, Beckmann M, Parry A, Mclntyre HD. Barriers and enablers to translating gestational diabetes guidelines into practice. Practical Diabetes. 2014;31(2):67-72a. doi:10.1002/pdi.1833.

21. Heslehurst N, Newham J, Maniatopoulos G, Fleetwood C, Robalino S, Rankin J. Implementation of pregnancy weight management and obesity guidelines: a meta-synthesis of healthcare professionals' barriers and facilitators using the Theoretical Domains Framework. Obes Rev. 2014;15(6): 462-86. doi:10.1111/obr.12160.

22. Lipworth W, Taylor N, Braithwaite J. Can the theoretical domains framework account for the implementation of clinical quality interventions? BMC Health Serv Res. 2013;13(1):1-13. doi:10.1186/1472-6963-13-530.

23. Middleton S, Levi CR, D'Este C, Grimshaw J, Cadilhac DA, Considine J, et al. $\mathrm{T}^{3}$ Trial protocol: A CRCT evaluating an organisational intervention to improve triage, treatment and transfer of stroke patients in EDs. Int J Stroke. 2013;8(S1):10.

24. Daniels SK, Anderson JA, Petersen NJ. Implementation of stroke dysphagia screening in the emergency department. Nursing Research and Practice. 2013. doi:10.1155/2013/304190.

25. Grady A, Bryant J, Carey M, Paul C, Sanson-Fisher R. Enablers of the implementation of tissue plasminogen activator in acute stroke care: a cross-sectional survey. PLoS ONE. 2014; doi: http://dx.doi.org/10.1371/ journal.pone.0114778

26. Hargis M, Shah JN, Mazabob J, Rao CV, Suarez Jl, Bershad EM. Barriers to administering intravenous tissue plasminogen activator (tPA) for acute ischemic stroke in the emergency department: a cross-sectional survey of stroke centers. Clin Neurol Neurosurg. 2015;135:79-84. doi: http://dx.doi.org/ 10.1016/j.clineuro.2015.04.027.

27. Meurer WJ, Majersik JJ, Frederiksen SM, Kade AM, Sandretto AM, Scott PA. Provider perceptions of barriers to the emergency use of tPA for acute ischemic stroke: a qualitative study. BMC Emerg. 2011; doi: http://dx.doi.org/ 10.1186/1471-227X-11-5

28. Stecksén A, Lundman B, Eriksson M, Glader E-L, Asplund K. Implementing thrombolytic guidelines in stroke care: perceived facilitators and barriers. Qual Health Res. 2014. doi:10.1177/1049732313514137.

29. Williams JM, Jude MR, Levi CR. Recombinant tissue plasminogen activator (rt-PA) utilisation by rural clinicians in acute ischaemic stroke: a survey of barriers and enablers. Aust J Rural Health. 2013; doi: http://dx.doi.org/10. 1111/ajr.12052
30. Gache K, Leleu H, Nitenberg G, Woimant F, Ferrua M, Minvielle E. Main barriers to effective implementation of stroke care pathways in France: a qualitative study. BMC Health Serv Res. 2014;14:95.

31. Johnson M, Cohn J, Bakas T. Emergency department nurses' perceived barriers and facilitators to caring for stroke patients. J Neurosci Nurs. 2011; 43(5):238-43.

32. Van Der Weijden T, Hooi JD, Grol R, Limburg M. A multidisciplinary guideline for the acute phase of stroke: barriers perceived by Dutch neurologists. J Eval Clin Pract. 2004;10:241-6.

33. Critical Appraisal Skills Programme(CASP).CASP Qualitative Checklist. http://media.wix.com/ugd/dded87_29c5b002d99342f788c6ac670e49f274. pdf. Accessed 15 Dec 2015

34. Center for Evidence-based Management (CEBMa). Critical Appraisal of a Survey. http://www.cebma.org/wp-content/uploads/Critical-AppraisalQuestions-for-a-Survey.pdf. Accesssed 15 Dec 2015

35. Cane J, Richardson M, Johnston M, Ladha R, Michie S. From lists of behaviour change techniques (BCTs) to structured hierarchies: comparison of two methods of developing a hierarchy of BCTs. Br J Health Psychol. 2015;20(1):130-50. doi:10.1111/bjhp.12102.

36. Michie S, Richardson M, Johnston M, Abraham C, Francis J, Hardeman W, et al. The behavior change technique taxonomy (v1) of 93 hierarchically clustered techniques: building an international consensus for the reporting of behavior change interventions. Ann Behav Med. 2013;46(1):81-95. doi:10.1007/s12160-013-9486-6.

37. Caplan LR. Stroke thrombolysis: slow progress. Circulation. 2006;114(3): 187-90. doi:10.1161/circulationaha.106.638973.

38. Goldstein JN, Marrero M, Masrur S, Pervez M, Barrocas AM, Abdullah A, et al. Management of thrombolysis-associated symptomatic intracerebral hemorrhage. Arch Neurol. 2010;67(8):965-9. doi:10.1001/archneurol.2010.175.

39. Wilson TD, Dunn DS. Effects of introspection on attitude-behavior consistency: analyzing reasons versus focusing on feelings. J Exp Soc Psychol. 1986;22(3):249-63.

40. Nilsen P. Making sense of implementation theories, models and frameworks. Implement Sci. 2015;10:53. doi:10.1186/s13012-015-0242-0.

41. Paul CL, Ryan A, Rose S, Attia JR, Kerr E, Koller C, et al. How can we improve stroke thrombolysis rates? A review of health system factors and approaches associated with thrombolysis administration rates in acute stroke care. Implement Sci. 2016;11(1):1-12. doi:10.1186/s13012-016-0414-6.

42. Duncan E, Murray J. The barriers and facilitators to routine outcome measurement by allied health professionals in practice: a systematic review. BMC Health Serv Res. 2012;12(1):96.

43. Tavender EJ, Bosch M, Gruen RL, Green SE, Michie S, Brennan SE, et al. Developing a targeted, theory-informed implementation intervention using two theoretical frameworks to address health professional and organisational factors: a case study to improve the management of mild traumatic brain injury in the emergency department. Implement Sci. 2015;10:74.

44. Slot KB, Berge E. Thrombolytic treatment for stroke: patient preferences for treatment, information, and involvement. J Stroke Cerebrovasc Dis. 2009; 18(1):17-22. doi: http://dx.doi.org/10.1016/j.jstrokecerebrovasdis.2008.06.009.

45. Moss C. Patients' perspectives on the impact of fasting while in hospital. Evidence Based Nursing. 2016. doi:10.1136/eb-2015-102166.

\section{Submit your next manuscript to BioMed Central and we will help you at every step:}

- We accept pre-submission inquiries

- Our selector tool helps you to find the most relevant journal

- We provide round the clock customer support

- Convenient online submission

- Thorough peer review

- Inclusion in PubMed and all major indexing services

- Maximum visibility for your research

Submit your manuscript at www.biomedcentral.com/submit

) Biomed Central 